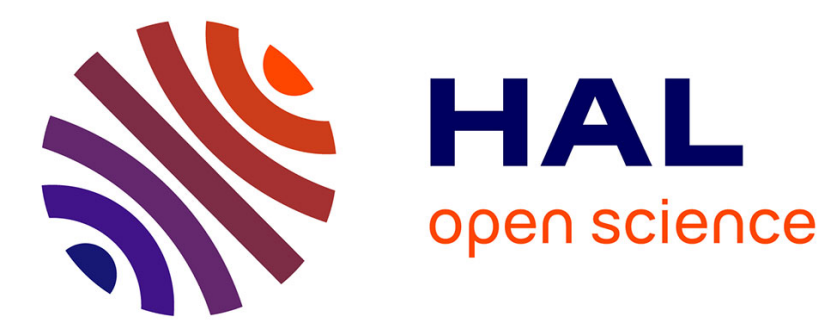

\title{
Carrier transport and trapping process in high-resistivity CdTe grown by a modified THM
}

\author{
T. Taguchi, J. Shirafuji, Y. Inuishi
}

\section{To cite this version:}

T. Taguchi, J. Shirafuji, Y. Inuishi. Carrier transport and trapping process in high-resistivity CdTe grown by a modified THM. Revue de Physique Appliquée, 1977, 12 (2), pp.189-193. 10.1051/rphysap:01977001202018900 . jpa-00244140

\section{HAL Id: jpa-00244140 https://hal.science/jpa-00244140}

Submitted on 1 Jan 1977

HAL is a multi-disciplinary open access archive for the deposit and dissemination of scientific research documents, whether they are published or not. The documents may come from teaching and research institutions in France or abroad, or from public or private research centers.
L'archive ouverte pluridisciplinaire HAL, est destinée au dépôt et à la diffusion de documents scientifiques de niveau recherche, publiés ou non, émanant des établissements d'enseignement et de recherche français ou étrangers, des laboratoires publics ou privés. 


\title{
CARRIER TRANSPORT AND TRAPPING PROCESS IN HIGH-RESISTIVITY CdTe GROWN BY A MODIFIED THM
}

\author{
T. TAGUCHI, J. SHIRAFUJI and Y. INUISHI \\ Department of Electrical Engineering, Faculty of Engineering, Osaka University Suita, Osaka, Japan
}

\begin{abstract}
Résumé. - On a étudié les propriétés de piégeage et de dépiégeage des porteurs dans le tellurure de cadmium par la méthode du temps de vol. Les cristaux semi-isolants de type pétaient préparés par une méthode THM en solvant avec adjonction d'un réservoir de cadmium. On a observé, pour les électrons un centre de piégeage situé à $0,05 \mathrm{eV}$ au-dessous de la bande de conduction et pour les trous, un niveau localisé à $0,14 \mathrm{eV}$ environ au-dessus de la bande de valence. Ce résultat a été obtenu en supposant la présence d'un seul niveau respectivement pour les électrons et les trous. L'influence de la pression de cadmium sur les propriétés de piégeage des matériaux sera discutée. Les meilleurs valeurs du temps de piégeage que nous ayons obtenues sont de $360 \mathrm{~ns}$ pour les électrons et $1,0 \mu$ s pour les trous pour une supression de cadmium de $5 \times 10^{-3}$ atm environ.
\end{abstract}

\begin{abstract}
Carrier trapping and detrapping processes in high-resistivity p-type crystals grown by a travelling heater method which is modified to provide a Cd reservoir (modified THM) have been investigated using a time-of-flight method. It is found that the trapping centers are located at about $0.05 \mathrm{eV}$ below the conduction band for electrons and at about $0.14 \mathrm{eV}$ above the valence band for holes, respectively. The carrier transport properties have been simply analyzed by assuming the presence of only one type trap level for electrons and holes, respectively. The influence of the Cd overpressure on carrier trapping and detrapping is discussed. The best values of the

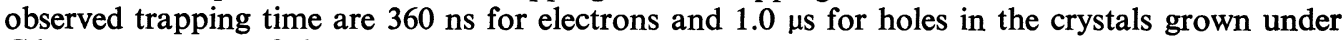
Cd over-pressures of about $5 \times 10^{-3} \mathrm{~atm}$.
\end{abstract}

1. Introduction. - Recent results of studies on carrier transport in high-purity CdTe crystals have indicated that the presence of certain trapping centers is a major factor limiting the performance of radiation detectors. Mayer et al. [1] by the time of flight method using $\alpha$-particle irradiation have shown that a deep electron trap lies at about $0.6 \mathrm{eV}$ below the conduction band in semi-insulating crystals grown by the Bridgman method. Ottaviani et al. [2] and Martin et al. [3] have investigated the trapping and detrapping processes both for electrons and holes in crystals grown by the regular THM method ; employing the time-offlight method with pulsed electron bombardment. Recently, Martin et al. [4] have identified the existence of shallow and deep trapping levels for both electrons and holes using thermally stimulated current measurements.

This paper discusses trapping and detrapping effects in high-resistivity CdTe single crystals $[5,6]$ grown by a travelling heater method using a controlled Cd overpressure. Injection of carriers in the time-of-flight method is achieved by a short pulse of a $\mathrm{N}_{2}$ laser. It appears that the crystals grown by this modified THM yield better properties in comparison with undoped or Cl-doped ones prepared by the usual THM [7]. In the crystals grown under a low $\mathrm{Cd}$ over-pressure $\left(<10^{-3} \mathrm{~atm}\right)$ in the modified THM, detrapping effects at room temperature for electrons are not observed. In the case of holes, the detrapping effects are due to the thermal release of carriers trapped on a level lying at $0.14 \mathrm{eV}$ above the valence band. This levellis identical with the acceptor at $E_{\mathrm{v}}+0.15 \mathrm{eV}$ which has been observed by measurements of the Hall effect $[8,9]$ and photoluminescence [10]. It is found that the detrapping processes for holes become dominant when increasing the $\mathrm{Cd}$ over-pressure; this appears to be related to the enhancement of the emission intensity of the $1.42 \mathrm{eV}$ band.

2. Experimental procedures. - Undoped and $\mathrm{Cl}$-doped CdTe single crystals were grown from $\mathrm{Te}-$ solution by the standard THM. Also, the undoped p-type crystals used in this study were prepared by THM from Te-solution under a controlled Cd overpressure (this we shall call modified THM). Crystals obtained under a relatively low $\mathrm{Cd}$ over-pressure without intentional chemical impurities show p-type conduction with resistivities higher than $10^{6} \Omega-\mathrm{cm}$. Samples cut from an ingot were shaped into a thin plate of $10 \times 10 \times 1-2 \mathrm{~mm}^{3}$ and then $\mathrm{Au}$ was evaporated as electrode onto both surfaces after either chemical etching with Br-methanol solution or after only polishing.

Time-of-flight measurements were performed by using a short light pulse with $3 \mathrm{~ns}$ duration from a $\mathrm{N}_{2}$ laser. The sample was mounted on a $\mathrm{BeO}$ plate attached to a $\mathrm{Cu}$ cold finger in a cryostat. The light pulse was focussed through a quartz lens. The charge induced by the carrier drift in the sample was observed on an oscilloscope. The ambient temperature of samples was 
varied from 330 to $120 \mathrm{~K}$. In order to investigate the detrapping mechanism both for electrons and holes, white light from a W-lamp or monochromatic light from a GaAs light emitting diode was employed.

3. Results. - Figure 1 shows the transient charge waveform for holes and electrons at room temperature under an electric field of $1.3 \mathrm{kV} / \mathrm{cm}$ in undoped crystals

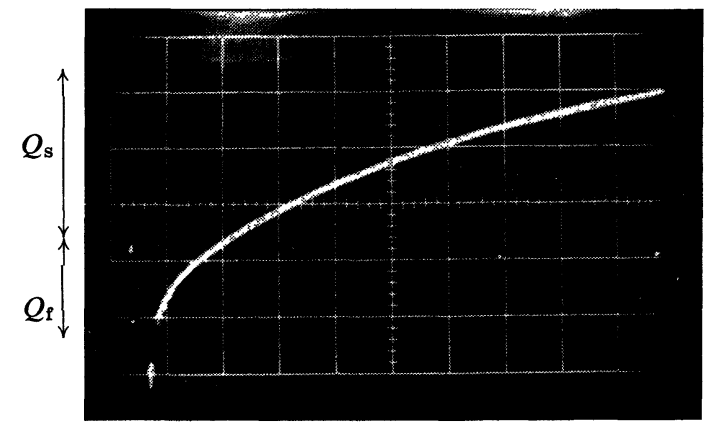

a) hole : Hori. $1 \mu /$ div. Vert. $20 \mathrm{mV} /$ div.

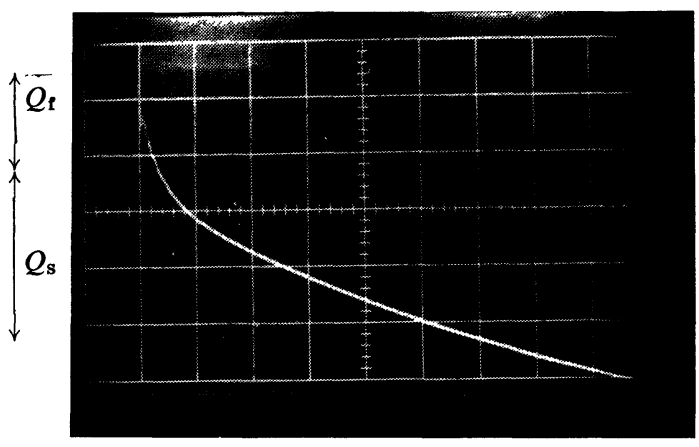

b) électron : Hori. $20 \mathrm{n} /$ div. Vert. $50 \mathrm{mV} /$ div.

Fig. 1. - Transient charge waveform for holes and electrons at room temperature under an electric field of $1.3 \mathrm{kV} / \mathrm{cm}$ in usual THM crystals. $Q_{\mathrm{f}}$ due to fast component, $Q_{\mathrm{s}}$ due to slow component.

grown by standard THM. This clearly shows two components with fast $\left(Q_{\mathrm{f}}\right)$ and slow $\left(Q_{\mathrm{s}}\right)$ rise times. The fast rise part depends on temperature only weakly both for holes and electrons, as will be shown later, however, the slow part both for holes and electrons is strongly dependent on the temperature of the samples. We believe that the slow component is due to the thermal release of carriers (electrons or holes), captured at the trapping center, into the conduction or the valence band, respectively. Therefore, with decreasing temperature the detrapping time $\left(\tau_{\mathrm{D}}\right)$ defined by following relation [11] becomes longer.

$$
\frac{1}{\tau_{\mathrm{D}}}=S \exp \left(-\frac{E_{\mathrm{T}}}{k \mathrm{~T}}\right)
$$

where $S$ is a frequency factor and $E_{\mathrm{T}}$ is the activation energy of the trapping center. Under certain conditions $\left(\tau_{\mathrm{D}} \gg \tau^{+} \gg T_{\mathrm{R}}\right)$ we can make a simple estimate of the trapping time $\left(\tau_{D}\right)$ for holes and electrons from the observed transient charge waveform using the following formula,

$$
Q_{\mathrm{S}}=Q_{0}\left[1-\exp \left(-\frac{t}{\tau_{\mathrm{D}}}\right)\right]
$$

where $Q_{0}$ indicates the saturation charge at $t \rightarrow \infty$.

Figures 2 and 3 show the temperature dependence of detrapping time for holes and electrons in the crystals grown by standard THM at an electric field of $1.8 \mathrm{k} V / \mathrm{cm}$, respectively. We obtain an activation energy $\left(E_{\mathrm{T}}\right)$ of about $0.14 \mathrm{eV}$ for holes and about $0.05 \mathrm{eV}$ for electrons from the slope of the semi-log plot, respectively. At room temperature the detrapping time of holes and electrons showed strong scatter from sample to sample. We observed that the event of detrapping for holes and electrons is very sensitive to illumination by infrared light. In particular, the

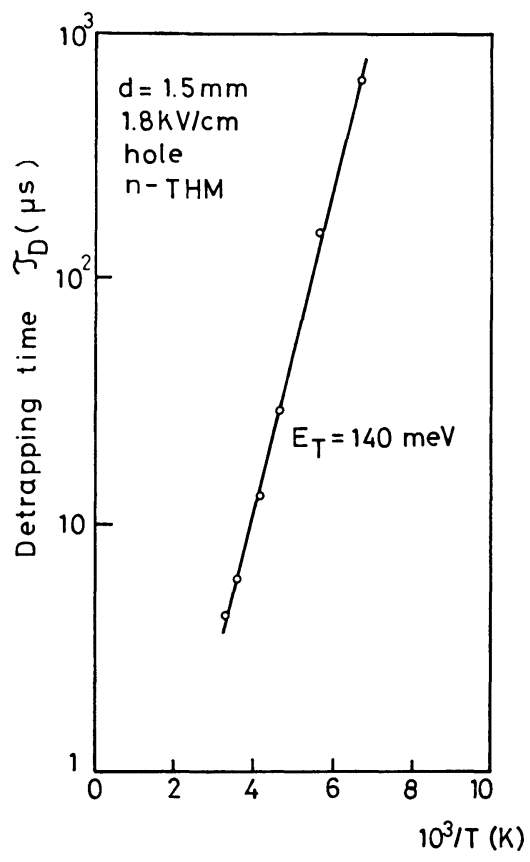

FIG. 2. - Temperature dependence of detrapping time of holes in usual THM crystals.

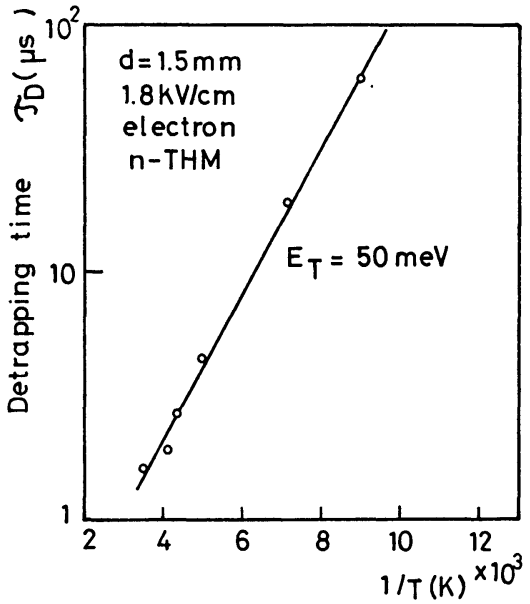

Fig. 3. - Temperature dependence of detrapping time of electrons in usual THM crystals. 
detrapping effects for holes vanished under the illumination of weak light emitted from a GaAs LED.

Figure 4 shows the room-temperature resistivity and the emission intensity of the $1.42 \mathrm{eV}$ band at $4.2 \mathrm{~K}$ as a function of $\mathrm{Cd}$ over-pressure in undoped p-type crystals grown by the modified THM. A detailed explanation about the growth and the character of the crystals is given elsewhere [6]. At lower $\mathrm{Cd}$ over-pressures (below about $7 \times 10^{-3} \mathrm{~atm}$ ), we have high-resistivity samples (over $10^{6} \Omega$-cm) without intentional doping with chemical impurities.

Figure 5A, $B$ and $C$ show the transient charge waveform for electrons and holes in the crystals prepared at the position of $a, b$ and $c$ described in figure 4 , respectively. With increasing $\mathrm{Cd}$ over-pressure the detrapping effect for electrons at low electric fields is clearly affected as shown in fig. $5 \mathrm{C}$.

The fast component both for electrons and holes which is shown in figure $5 \mathrm{~A}$ and $\mathrm{B}$ presents the initial response [12] for

$$
t \leqslant T_{\mathrm{R}}
$$

where $T_{\mathrm{R}}$ is transit time of carriers between electrodes. The transit time obeys the following relation

$$
T_{\mathrm{R}}=\frac{d^{2}}{\mu_{\mathrm{d}} V}
$$

where $\mu_{\mathrm{d}}$ is the drift mobility of carriers, $V$ the applied field and $d$ the thickness of the sample.
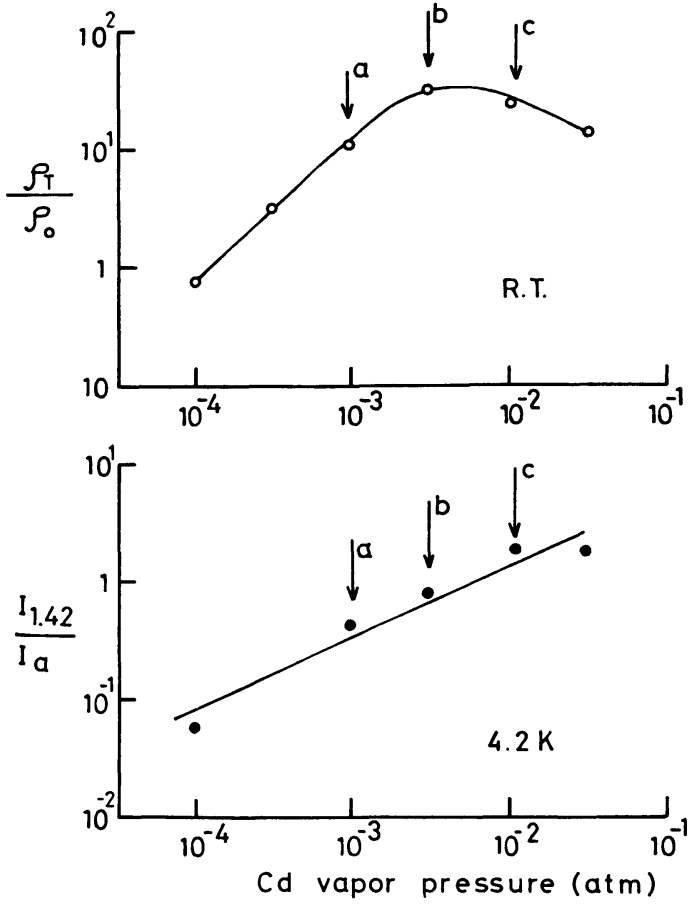

FIG. 4. - Room temperature resistivity and the emission intensity of the $1.42 \mathrm{eV}$ emission band at $4.2 \mathrm{~K}$ as a function of $\mathrm{Cd}$ over-pressure in crystals grown from a modified THM. $\rho_{0}$, room temperature resistivity of the original crystals grown from usual THM. $\rho_{\mathrm{T}}$, room temperature resistivity of the modified THM crystal. $I_{1.42}$, emission intensity of the $1.42 \mathrm{eV}$ band at $4.2 \mathrm{~K} . I_{\alpha}$, emission intensity of excitons [5] bound to neutral acceptor at $4.2 \mathrm{~K}$.

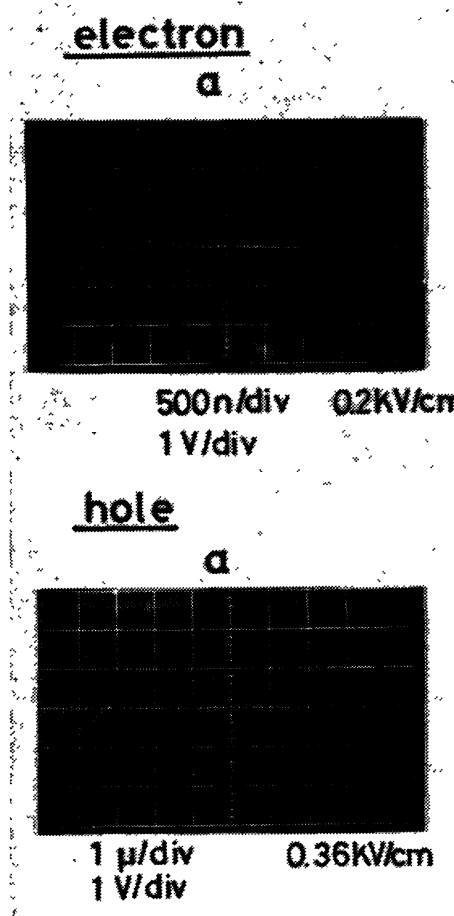

(A)

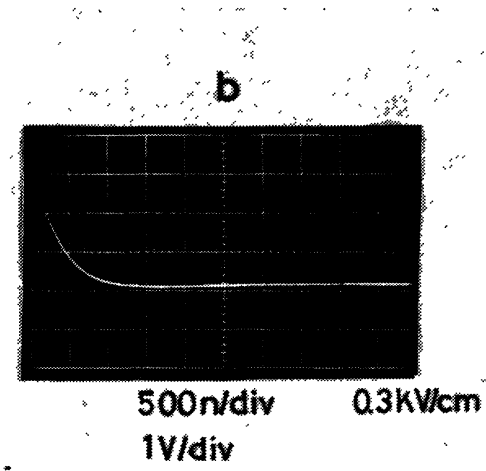

b

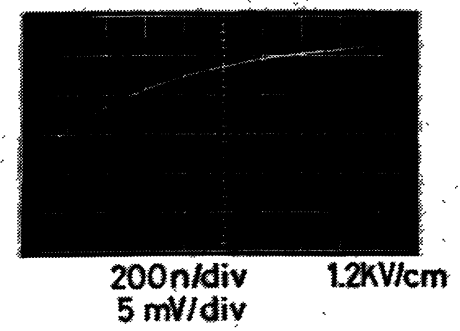

(B)

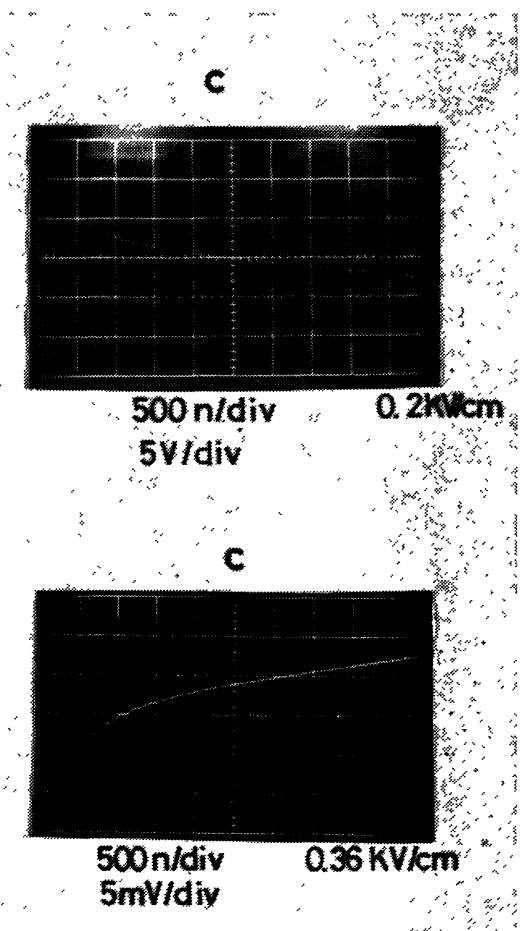

(C)

FIG. 5A, B and C. - Transient charge waveform for electrons and holes at room temperature in crystals grown from a modified THM. A), crystals at the position of a shown in figure B), crystals at. the position of $b$ shown in figure $4 \mathrm{C}$ ), crystals at the position of $\mathrm{c}$ shown in figure 4 . 
The fast component gives the mean time that the electron (or hole) is free before trapping and we shall call it the carrier trapping time $\left(\tau^{+}\right)$[13]. The value of $\tau^{+}$can be determined directly from the following equation $[12,13]$ (if $\tau^{+} \ll \tau_{\mathrm{D}}$ )

$$
Q(t)=\frac{e N_{0} \tau^{+} \mu_{\mathrm{d}} V}{d^{2}}\left[1-\exp \left(-\frac{t}{\tau^{+}}\right)\right]
$$

where $N_{0}$ are the initial carriers generated by the pulsed laser light, $\mu_{\mathrm{d}}$ drift mobility of carriers, $V$ applied voltage and $d$ the thickness of the sample. We can estimate the value of $\tau^{+}$from an analysis of the relation between $\log \left[{ }^{6} Q(t=\infty)-Q(t)\right]$ versus time $(t)$ for the case of figure $5 \mathrm{~A}$ and B. For example, in

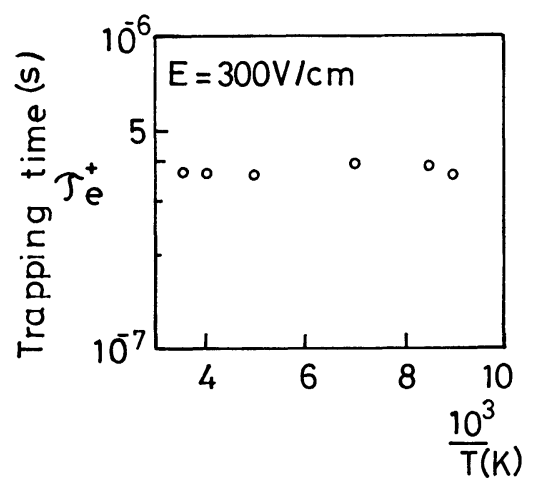

FIG. 6. - Temperature dependence of trapping time of electrons in crystals of B) in figure 5 . figure 5B we obtain the value of $360 \mathrm{~ns}$ for electrons and $1.0 \mu$ s for holes at room temperature, respectively.

Figure 6 shows the temperature dependence of the trapping time for electrons in the crystals grown from position of $b$ as shown in figure 4. The electrontrapping time is essentially temperature independent.

4. Discussion. - Transient measurements using the time-of-flight method permit the determination of the carrier-drift mobility $\left(\mu_{\mathrm{d}}\right)$, trapping and detrapping times $\left(\tau^{+}, \tau_{\mathrm{D}}\right)$, and $\left(\mu \tau^{+}\right)$products both for electrons and holes which are important factors in the performance of CdTe detectors.

If detailed balance considerations are applicable in our case, the ratio between $\tau^{+}$and $\tau_{\mathbf{D}}$ is given by the classical relation as follows $[12,13]$,

$$
\frac{\tau^{+}}{\tau_{\mathrm{D}}}=\frac{N_{\mathrm{v}, \mathrm{c}}}{N_{\mathrm{T}}} \exp \left(\frac{E_{\mathrm{T}}}{k \mathrm{~T}}\right)
$$

where $N_{\mathrm{v}, \mathrm{c}}$ describes the effective density of the valence band or conduction band, $N_{\mathrm{T}}$ trap density, $E_{\mathrm{T}}$ trap depth and $k$ is the Boltzmann factor. We can apply this then to the estimation of trap density by assuming one type of trap level in a weak electric field under the presence of trapping and detrapping effects.

4.1 COMPARISON BETWEEN «STANDARD » THM AND «MODIFIED » THM CRYSTALS. - To date the performance of CdTe detectors has been dominated by

TABle I

Characteristic of various p-type THM crystals and comparison between our results

\begin{tabular}{|c|c|c|c|c|c|c|c|c|c|c|c|c|c|}
\hline & Crystal & $\begin{array}{l}\text { Resisti- } \\
\text { vity } \\
(\Omega-\mathrm{cm})\end{array}$ & Trapp & $\begin{array}{l}\text { ing level } \\
\text { eV) }\end{array}$ & & $\begin{array}{l}\mu_{\text {de }} \\
\mathrm{n}^{2} / \mathrm{V} . \mathrm{s}\end{array}$ & $\begin{array}{l}\mu_{\mathrm{dh}} \\
\mathrm{s})\end{array}$ & & $\begin{array}{l}\tau_{\mathbf{h}}^{+} \\
\text {s) }\end{array}$ & \multicolumn{2}{|c|}{$\begin{array}{c}(\mu \tau) \\
\left(\mathrm{cm}^{2} / \mathrm{V} .\right)\end{array}$} & \multicolumn{2}{|c|}{$\begin{array}{l}\text { trap density } \\
\quad\left(\mathrm{cm}^{-3}\right)\end{array}$} \\
\hline \multirow{5}{*}{ Our } & \multirow[b]{2}{*}{$\begin{array}{c}\text { undoped } \\
\text { THM }\end{array}$} & \multirow[b]{2}{*}{$6 \times 10^{4}$} & electron & hole & \multirow[b]{2}{*}{90} & \multirow[b]{2}{*}{610} & \multirow[b]{2}{*}{81} & \multirow[b]{2}{*}{100} & \multirow[b]{2}{*}{250} & electron & hole & $\begin{array}{c}\text { electron } \\
\left(E_{\mathrm{c}}-0.05\right. \\
\mathrm{eV})\end{array}$ & $\begin{array}{c}\text { hole } \\
\left(E_{\mathrm{v}}+0.14\right. \\
\mathrm{eV})\end{array}$ \\
\hline & & & $\overline{E_{\mathrm{c}}-0.05}$ & $E_{\mathrm{v}}+0.14$ & & & & & & $6.1 \times 10^{-5}$ & $2 \times 10^{-5}$ & $1 \times 10^{17}$ & $6.4 \times 10^{17}$ \\
\hline & $\begin{array}{c}\text { Cl-doped } \\
\text { THM }\end{array}$ & $10^{8}$ & 0.06 & 0.14 & 62 & 740 & 44 & 160 & 500 & $1.4 \times 10^{-4}$ & $2.2 \times 10^{-5}$ & $4.5 \times 10^{16}$ & $6.4 \times 10^{16}$ \\
\hline & $\begin{array}{c}\text { undoped } \\
\text { modified } \\
\text { THM }\end{array}$ & $7 \times 10^{5}$ & 0.05 & 0.14 & 84 & 650 & 80 & 120 & 350 & $7.8 \times 10^{-5}$ & $2.8 \times 10^{-5}$ & 1017 & $5.1 \times 10^{16}$ \\
\hline & $\begin{array}{c}\text { undoped } \\
\text { modified } \\
\text { THM }\end{array}$ & $8 \times 10^{6}$ & $\begin{array}{c}\text { not-de- } \\
\text { tected }\end{array}$ & 0.14 & 94 & 1100 & 100 & 360 & 1000 & $4 \times 10^{-4}$ & $9.6 \times 10^{-5}$ & & $4.8 \times 10^{15}$ \\
\hline $\begin{array}{l}\text { Martin et al. } \\
\quad[3,4]\end{array}$ & $\begin{array}{c}\text { Cl-doped } \\
\text { THM }\end{array}$ & $(*)$ & 0.06 & 0.14 & $(*)$ & \begin{tabular}{|}
$800-$ \\
1000
\end{tabular} & $\begin{array}{r}45- \\
90\end{array}$ & 150 & 1200 & $(*)$ & $(*)$ & $(*)$ & $(*)$ \\
\hline Bell et al. [7] & $\begin{array}{l}\mathrm{Cl}, \mathrm{Br}- \\
\text { doped } \\
\text { THM }\end{array}$ & $10^{6}$ & $\begin{array}{l}0.02 \\
0.05\end{array}$ & $\begin{array}{l}0.14 \\
0.35\end{array}$ & 80 & $\begin{array}{lll}1 & 130\end{array}$ & 80 & $<40$ & $(*)$ & $10^{-3}$ & $2.5 \times 10^{-5}$ & $1 \times 10^{15}$ & $2.5 \times 10^{16}$ \\
\hline
\end{tabular}
and previous ones obtained by Martin et al. and Bell et al. at room temperature

(*) It is not clear because the value is not given in the literature. 
trapping and detrapping effects. In CdTe detectors, it has been known that the timing properties are controlled by the shallow levels $[4,7]\left(E_{c}-0.02 \mathrm{eV}\right.$ for electrons and $E_{\mathrm{v}}+0.14 \mathrm{eV}$ for holes) and the resolution is determined by deeper levels [7] $\left(E_{\mathrm{c}}-0.05 \mathrm{eV}\right.$ for electrons and $E_{\mathrm{v}} \sim+0.4 \mathrm{eV}$ for holes). We have observed that trapping centers occur at $0.05 \mathrm{eV}$ below the conduction band for electrons and at $0.14 \mathrm{eV}$ above the valence band for holes in undoped and Cl-doped crystals grown by standard THM. However, the shallow level at $E_{\mathrm{c}}-0.02 \mathrm{eV}$ for electrons and the deeper level at $E_{\mathrm{v}} \sim+0.4 \mathrm{eV}$ for holes have not been observed in our case. In modified THM crystals, with increasing $\mathrm{Cd}$ over-pressure the detrapping effect for electrons appeared and the trap level was estimated to be $0.05 \mathrm{eV}$ below the conduction band from the temperature dependence of the detrapping times. However, we have not observed the detrapping effect for electrons at room temperature in the modified THM crystals grown under Cd over-pressure of about $4 \times 10^{-3} \mathrm{~atm}$. It may be thought that this trapping center is related to the level found by the measurements of Hall effect [14] and photoluminescence [8]. However, the origin of the trapping center has not been clear so far. On the other hand, the trapping level at $0.14 \mathrm{eV}$ above the valence band for holes has been observed in all crystals investigated here. But these detrapping effects for holes vanished at room temperature under light of $8880 \AA$ emitted by a GaAs LED. The detrapping process for holes becomes dominant with increasing $\mathrm{Cd}$ over-pressure, and the $1.42 \mathrm{eV}$ emission band as shown in figure 4 is also enhanced. The detailed transport properties of holes trapped to this level have been first investigated by Ottaviani et al. in high-resistivity crystals grown from Bridgman [15] and THM [7]. They obtained a value of about $5 \times 10^{16} \mathrm{~cm}^{-3}$ for the density of the trap center at $E_{\mathrm{v}}+0.14 \mathrm{eV}$. In our case, the density of the trap at room temperature was estimated to be about $5 \times 10^{15}$. $1 \times 10^{17} \mathrm{~cm}^{-3}$ in the modified THM crystals.

5. Conclusion. - Carrier trapping and detrapping effects in high-resistivity p-type crystals grown from a modified THM have been investigated using a time-offlight method.

We can summarize the results obtained as follows :

1) Trapping centers for electrons and holes are located at $0.05 \mathrm{eV}$ below the conduction band and at $0.14 \mathrm{eV}$ above the valence band, respectively.

2) The trapping effect for holes is related to the enhancement of the $1.42 \mathrm{eV}$ emission band.

3) The detrapping effect for electrons at room temperature does not occur in the modified THM crystals grown under $\mathrm{Cd}$ vapor pressure of about $5 \times 10^{-3} \mathrm{~atm}$, and the best values of the observed trapping time are $360 \mathrm{~ns}$ for electrons and $1.0 \mu$ s for holes at room temperature.

4) The trap density, simply estimated by assuming the presence of one trap level each for electrons and holes, leads to a value of about $5 \times 10^{15} \mathrm{~cm}^{-3}$ for hole-trapping centers in the best crystals.

\section{References}

[1] Mayer, J., Akutagawa, W. M. and Kikuchi, R., J. Appl. Phys. 39 (1968) 2818.

[2] Ottaviani, G., Canali, C. and Alberiqui Quaranta, A., IEEE Trans. NS-22 (1975) 192.

[3] Martin, G., Bach, P., Trandart, J. C. and Fabre, E., ibid. 226.

[4] Martin, G., Fabre, E., Fogarassy, E. and NGo-TichPHUOC, ibid. NS-23 (1976) 154.

[5] Taguchi, T., Shirafuji, J. and INUishi, Y., Japan. J. Appl. Phys. Suppl. 15 (1976) 267.

[6] Taguchi, T., Shirafuji, J. and InUishi, Y., to be published in this issue.

[7] Bell, R. O., Wald, F. V., Canali, C., Nava, F. and OtTAVIANI, G., IEEE Trans. NS-21 (1974) 331.

[8] Taguchi, T., ShiRAfuji, J. and InUishi, Y., Japan. J. Appl. Phys. 13 (1974) 1003.
[9] Rud, Yu. V. and SANin, K. V., Sov. Phys.-Semicond. 5 (1971) 244.

[10] Taguchi, T., Shirafuji, J. and InUishi, Y., Japan. J. Appl. Phys. 12 (1973) 1558.

[11] Martini, M., Mayer, J. W. and Zanio, K. R., Applied Solid State Science 3 (1972) 182 (Ed. R. Wolfe, Academic Press, New York) 1972.

[12] Semiconductor Radiation Detectors, edited by G. Bertolini and A. Coche (North-Holland, Amsterdam) 1968, Chap. 5.

[13] MAYer, J., ZANio, K. R., MARTini, M. and Fowler, I. L., IEEE Trans. NS-20 (1973) 221.

[14] KIKUCHI, C., Rad. Eff. 8 (1971) 249.

[15] Ottaviani, G., Canali, C., Jacoboni, C., Alberigi Quaranta, A. and Zanio, K., J. Appl. Phys. 44 (1973) 360. 